\title{
Photoprotection in Outdoor Sports: A Review of the Literature and Recommendations to Reduce Risk Among Athletes
}

\author{
Yolanda Gilaberte (D) - Carles Trullàs (D) · Corinne Granger (D) • \\ Magdalena de Troya-Martín (D)
}

Received: October 29, 2021 / Published online: January 29, 2022

(C) The Author(s) 2022

\begin{abstract}
Solar exposure, for long hours and often at peak times with limited shade available, predisposes athletes to episodic sunburn and chronic damage, causing increased risk of precancerous lesions and skin cancer. Environmental factors and training intensity affect risk. Clothing provides good protection, but changing established "uniforms" may not be possible for reasons of practicality, safety, or simply custom. Although physical activity should be encouraged for its physical and mental benefits, risk of skin damage should be minimised. We review existing behaviours, skin cancer risk, and campaigns in the sporting population and highlight key recommendations to help sun protection practices become engrained in sports practice.
\end{abstract}

Keywords: Sports; Athletes; Solar; Ultraviolet; Photoprotection; Skin; Cancer

Y. Gilaberte $(\bowtie)$

Department of Dermatology, Miguel Servet

University Hospital IIS Aragon, Paseo Isabel la

Católica, 3, 50009 Zaragoza, Spain

e-mail: ygilaberte@salud.aragon.es

C. Trullàs · C. Granger

ISDIN, Provençals 33, 08019 Barcelona, Spain

M. de Troya-Martín

Department of Dermatology, Hospital Costa del Sol,

Marbella, Spain

\section{Key Summary Points}

Duration and timing of sun exposure, and extreme training and environmental conditions increase the risk of skin damage, including precancerous and cancerous lesions.

Use of protective clothing and sunscreens is suboptimal; sunburn is common.

Sunburn rates remain high, as do markers of skin damage.

Sun protection practices should be an integral part of sports training; suitable products and authoritative encouragement may help improve this.

\section{INTRODUCTION}

Athletes are prone to a variety of skin conditions [1], but those who train outdoors have the added hazard of solar exposure. Exercise is associated with better overall health and should be encouraged [2], but protection against risks is warranted. Exposure patterns vary, from intermittent sunburn-inducing training at peak hours to large cumulative exposures [3], contributing to risk of melanoma and keratinocyte 
carcinoma (KC) (previously termed nonmelanoma skin cancer or NMSC) $[4,5]$.

Geographical factors affect ultraviolet (UV) radiation levels: snow reflection [6] and thinner air and ozone mean the peak UV index (UVI) can be $20-30 \%$ higher on a ski field (at $2.1 \mathrm{~km}$ altitude) than at sea level [7]. Indeed, without sunscreen, skiers can begin to burn after only $6 \mathrm{~min}$ (at $3.4 \mathrm{~km}$ altitude) [8].

Physiological factors also come into play: sweating can increase the skin's photosensitivity, as indicated by a decrease in the minimal erythema dose (MED, the minimal amount of radiation required to induce erythema) [9], due to a shift in the wavelengths absorbed by the stratum corneum and a decrease in reflection and refraction [10]. Furthermore, high-intensity and endurance exercise have been shown to negatively affect immune status [11] and antioxidant capacity [12].

We aimed to provide a comprehensive overview of the sun protection habits and needs of outdoor sports participants, taking into account skin cancer rates and the impact of previous educational interventions.

\section{METHODS}

We performed a literature search (March 2021) in PubMed using the terms sports AND skin AND sun, without date restrictions, yielding 306 articles. Titles and abstracts were reviewed for relevance. Articles in English or Spanish were accepted. In articles of uncertain relevance, the whole article was reviewed to determine its inclusion. Recommendations were based on this literature and the clinical experience of those authors who are clinical dermatologists, then discussed with the photoprotection board of ISDIN to identify any key missing areas.

This article is based on previously conducted studies and does not contain any new studies with human participants or animals performed by any of the authors.

\section{RESULTS}

\section{Existing Photoprotection Habits}

A range of study variables are reported, including exposure times, use of sunscreens and clothing, sunburn rates, skin examination practices, demographic differences, and the motivations for certain behaviours.

\section{Exposure Times}

De Castro-Maqueda et al. found that elite water sports athletes were exposed for around $4 \mathrm{~h}$ per day [13], and elite kitesurfers for $13.93 \mathrm{~h}$ per week [14], of whom only $6.9 \%$ avoided peak hours [14]. In runners in Portugal, 19\% trained between $10 \mathrm{am}$ and $6 \mathrm{pm}$ [15]; in Brazil, 57\% trained before $10 \mathrm{am}$ [16]. Teenage skateboarders (Spain) spent more than 90 days per year and at least $5 \mathrm{~h}$ a day outdoors [17]. Collegiate athletes (USA) spent an average $4 \mathrm{~h}$ per day and 10 months per year training outdoors [18]. The doses of UV exposure are summarised in Table 1.

\section{Use of Sunscreen and Other Protective Measures}

In an Australian study of mixed sports (soccer, hockey, surf lifesaving and tennis) in 18- to 30 -year-olds, almost half used sunscreen inadequately and almost one third did not use it at all [19]. In another study of mixed sports, $29.5 \%$ reported no sunscreen use, and only $20.2 \%$ had adequate use (sun protection factor [SPF] at least 30 with reapplication) [20]. Lawler et al. noted respective sports' rules influenced behaviours [21]. In elite rugby, field hockey, and rowing athletes in New Zealand, although 66\% were concerned about skin cancer, only $9 \%$ always applied sunscreen before going out in the sun, and one third reported intentionally tanning [22]. In collegiate athletes [18], although almost all (96\%) thought that sunscreen helps prevent skin cancer, more than half never used it.

A survey of retired Australian cricketers (mean age, 45 years) [23] found that hats were the most popular method, with $65.9 \%$ always wearing one during matches, followed by long- 
Table 1 Ultraviolet doses reported in previous studies

\begin{tabular}{|c|c|c|}
\hline $\begin{array}{l}\text { Study: } \\
\text { author, year }\end{array}$ & Details & UV dose \\
\hline $\begin{array}{l}\text { Serrano } \\
\text { et al. } 2010 \\
{[65]}\end{array}$ & $\begin{array}{l}\text { Cycling training camp, Valencia, Spain } \\
\text { Dosimeters on helmet }\end{array}$ & $\begin{array}{l}\text { Mean 2-day personal UV exposure of } \\
32.24 \pm 4.14 \mathrm{SED}^{\mathrm{a}} \text { in summer; } \\
11.30 \pm 5.36 \mathrm{SED} \text { in winter }\end{array}$ \\
\hline $\begin{array}{l}\text { Serrano } \\
\text { et al. } 2011 \\
{[66]}\end{array}$ & $\begin{array}{l}\text { Mixed sports clubs, Valencia, Spain: mountaineers, } \\
\text { tennis players, runners } \\
\text { Dosimeters, various sites }\end{array}$ & $\begin{array}{l}\text { Mean personal UV exposure of } 9.48 \pm 3.23 \text { SED } \\
\text { daily for mountaineers } \\
10.65 \pm 1.57 \text { SED for } 2 \text { days of training for tennis } \\
\text { players } \\
7.62 \pm 4.28 \text { SED for } 5 \text { days of training for runners }\end{array}$ \\
\hline $\begin{array}{l}\text { Serrano } \\
\text { et al. } 2013 \\
{[67]}\end{array}$ & $\begin{array}{l}\text { Child skiers, Huesca, Spain } \\
\text { Dosimeters on shoulders }\end{array}$ & $\begin{array}{l}\text { Median daily SED of } 2.1 \text { (range } 4.9-0.71 \text { ), equal to } \\
\text { approx. } 35 \% \text { of the } 24 \mathrm{~h} \text { ambient UV radiation on } \\
\text { the horizontal plane }\end{array}$ \\
\hline $\begin{array}{l}\text { Serrano } \\
\text { et al. } 2014 \\
{[68]}\end{array}$ & $\begin{array}{l}\text { Hikers, tennis players, runners; Valencia, Spain } \\
\text { Dosimeters, various sites }\end{array}$ & $\begin{array}{l}\text { Median personal UV exposure was } 8.1 \text { SED per day } \\
\text { for hikers; } 7.5 \text { SED per day of training for tennis } \\
\text { players; about } 2 \text { SED per competition day for } \\
\text { runners }\end{array}$ \\
\hline $\begin{array}{l}\text { Moehrle } \\
\text { et al. } 2000 \\
{[60]}\end{array}$ & $\begin{array}{l}\text { Professional cyclists, Tour de Suisse, Switzerland } \\
\text { Dosimeters on back of jersey }\end{array}$ & Mean daily personal exposure of $8.1 \mathrm{MED}^{\mathrm{b}}$ \\
\hline $\begin{array}{l}\text { Moehrle } \\
2000[69]\end{array}$ & $\begin{array}{l}\text { Ironman triathlon }(N=3) \text {, Hawaii, USA } \\
\text { Dosimeters on back }\end{array}$ & $\begin{array}{l}\text { Mean personal UV exposure of } 8.3 \text { MED for the } \\
\text { whole competition (approx. 8-9 h) }\end{array}$ \\
\hline $\begin{array}{l}\text { Rigel et al. } \\
2003[63]\end{array}$ & $\begin{array}{l}\text { Professional ski instructors, Vail, Colorado, USA } \\
\text { Digital dosimeters }\end{array}$ & $\begin{array}{l}\text { Mean daily mean UVB exposure was } 62.08 \mathrm{~mJ} / \mathrm{cm}^{2} \\
\left.\text { (range } 12-185 \mathrm{~mJ} / \mathrm{cm}^{2}\right)(0.5-7.6 \text { times MED for } \\
\text { type II skin) } \\
\text { Mean daily UVA exposure was } 10.6 \text { (range } 0.5-28 \mathrm{~J} / \\
\left.\mathrm{cm}^{2}\right)(0.55 \text { of minimum melanogenic dose) }\end{array}$ \\
\hline $\begin{array}{l}\text { Downs et al. } \\
2009[62]\end{array}$ & $\begin{array}{l}\text { Golfers, Queensland Australia during summer and } \\
\text { winter months. } 2 \text { recreational golfers vs } 2 \text { office } \\
\text { workers, assuming one 9-hole game/week; } 2-2.5 \mathrm{~h} \\
\text { Calibrated polysulfone dosimeter }\end{array}$ & $\begin{array}{l}\text { Estimated annual exposure: SED of } 817 \text { and } 839 \text { for } \\
\text { forearm and upper back, respectively }\end{array}$ \\
\hline $\begin{array}{l}\text { Downs et al. } \\
2020[64]\end{array}$ & $\begin{array}{l}\text { Olympic mixed sports, dose calculation for athletes } \\
\text { due to compete in Tokyo } 2020\end{array}$ & $\begin{array}{l}\text { Events lasting } 2 \mathrm{~h} \text { or more had personal erythematic } \\
\text { exposures in excess of } 200 \mathrm{~J} / \mathrm{m}^{2}\end{array}$ \\
\hline
\end{tabular}


Table 1 continued

\begin{tabular}{llc}
\hline $\begin{array}{l}\text { Study: } \\
\text { author, year }\end{array}$ & Details & UV dose \\
\hline $\begin{array}{l}\text { Gurrea Ysasi } \\
\text { et al. } 2014\end{array}$ & Golfers, winter (January), Valencia, Spain & Mean daily UVER exposure: head 2.07 \pm 0.80 SED, \\
[70] & & wrist $1.62 \pm 0.77$ SED. Mean exposure per hour \\
\hline
\end{tabular}

Exposure limit 0.3 MED per $8 \mathrm{~h}[61]$

SED standard erythema dose, MED minimal erythema dose, UVER ultraviolet erythematic radiation

${ }^{a}$ Standard erythema dose (SED) is used as a standardised measure of erythemogenic UV radiation. 1 SED is equivalent to an erythemal effective radiant exposure of $100 \mathrm{~J} / \mathrm{m}^{2}$

${ }^{b}$ One MED corresponds to $250 \mathrm{~J} / \mathrm{m}^{2}$ at $298 \mathrm{~nm}$, enough to induce erythema in non-tanned Caucasian skin (phototype II) [60]. The term MED has been used widely as a 'measure' of erythemal radiation. MED is the lowest erythemal effective radiant exposure that produces the first perceptible unambiguous erythema

sleeve shirt use (19.5\% "always") and sunscreen use (15\% "always").

Among Austrian marathon runners, most $(96.7 \%)$ wore shorts and short-sleeved $(87.6 \%)$ or sleeveless $(11.0 \%)$ shirts, and just over half (56.2\%) used sunscreen regularly [12]. In Portugal, only $23.5 \%$ of runners had adequate sun protection behaviour; $17 \%$ always used a hat, $12 \%$ consistently applied sunscreen before training, and $4 \%$ used a long-sleeved shirt [15]. In marathon runners in Spain, sunglasses (66.4\%) and sunscreen (58.2\%) were the most common practices, with less habitual use of a hat $(33.6 \%)$ or long-sleeved clothing (10.9\%) [24]. A similar pattern was observed in mountain marathon runners in Spain [25]. In Brazil, $86 \%$ of runners wore clothing or accessories for sun protection; $62 \%$ wore sunscreen, which was usually only applied to the face, and 53\% used SPF greater than 30 [16].

The most common practices among Spanish cyclists [26] were use of a hat (95.5\%) and sunglasses $(92.8 \%)$; the least common were longsleeved shirts and long trousers $(6.2 \%)$ and seeking shade (23.1\%). Only 39.2\% applied sunscreen [27].

Skiers and snowboarders [28] had "inconsistent" compliance with recommendations in a study of more than 4000 adults in western North America: only $4.4 \%$ complied with all advice [28]. Of those wearing sunscreen, most $(73.2 \%)$ applied it $30 \mathrm{~min}$ before exposure, but only $20.4 \%$ reapplied after $2 \mathrm{~h} \mathrm{[28].}$
Among surfers, windsurfers and Olympic sailors from 30 countries, aged 16-30 years, sunscreen was the most-used form of photoprotection, yet $22.5 \%$ reported never using it, and $31.1 \%$ did not reapply after $2 \mathrm{~h}$ [13], with some differences in habits among different sports. In the 2019 Para World Sailing Championships, elite sailors with disabilities from 19 countries reported a very low rate $(28.6 \%)$ of avoidance of midday sun and insufficient sunscreen reapplication $(33.9 \%$ did not reapply at all and $16.1 \%$ reapplied every $1-2 \mathrm{~h}$ ); use of sunglasses $(85.7 \%)$, sunscreen $(83.9 \%)$ and hat (75\%) fared better [26]. In handball players, approximately half did not apply sunscreen at all when training or competing [29].

Teenage skateboarders in Spain [17] were found to wear long-sleeved shirts (65.9\%); however, only $18.7 \%$ used sunscreen while skating, compared with a $33.3 \%$ rate in the same group when at the beach. Less than $40 \%$ reported habits like staying in the shade, wearing a hat, sunglasses, or avoiding peak hours [17].

In mountain guides [30], 34.4\% reported using sunscreen occasionally, rarely, or never. Of those who did use it, around one third wore SPF less than 30. Long-sleeved shirts were worn by $16.1 \%$, long trousers by $43.5 \%$, and hats by $79.0 \%$. A later study in a similar population found that $86 \%$ used sunscreen often or always [31]. 
Even in athletes who were transplant recipients-and therefore immunosuppressed with increased risk of photo-induced skin cancers$31 \%$ did not use sunscreen regularly, despite recognising the importance of photoprotection [32].

\section{Sunburn Rates}

Reports of sunburn during the previous season range from 19.7\% in Brazilian runners [16] up to $84.7 \%$ in elite kitesurfers [14]. Among adults in the US general population, increased levels of physical activity have been associated with higher levels of sunburn [33]. Wysong et al. compared sunburn rates in athletes vs the general population of a similar age: while $86 \%$ of athletes reported burns in the past year, only between one third and one half of the general population did [18].

Using erythema as a surrogate for skin cancer risk is reasonable, but self-reported erythema will probably be underestimated. Petersen et al. [34] found that researchers detected up to $28 \%$ more of objectively measured erythema than subjects did, concluding that erythema was "considerably underestimated"; in skiers, they found agreement between subjects and researchers in just 57\% [34]. Another limitation of using sunburn as an indicator of risk is that skin phototypes that do not burn easily are still exposed to dangerous radiation, and that longterm sub-erythemogenic doses can still cause DNA mutation [35]. Furthermore, keratinocyte carcinoma, in particular squamous cell carcinoma (SCC), correlates more with chronic exposure rather than burn episodes [36].

\section{Skin Examinations}

Zink et al. found that around $50-60 \%$ of mountain guides $[30,31]$ had undergone dermatological examination by a medical professional, with significant differences according to age, education, number of tours per month, and knowledge regarding skin cancer screening [31]. De Castro-Maqueda reported $83.3 \%$ of elite water sports athletes had not had a medical skin examination, and $87.5 \%$ did not self-examine their skin [30]; 87-95\% of handball players had not examined their skin over the last year [29]; and $78.8 \%$ of kitesurfers had not examined their skin during the previous year, but $54.2 \%$ had consulted a dermatologist [37]. Sixty percent of marathon runners in Austria had never had their naevi checked by a dermatologist [38]. Among Spanish cyclists $61.0 \%$ did not examine their skin regularly [27].

\section{Subgroup Differences}

Several studies have analysed which variables are predictors of sun-safe behaviour in sporting populations. In some, patterns mirror the general population, but others have found no significant differences among population subgroups $[13,22]$. The main patterns reported are those of safer behaviour in older, female athletes $[4,6,15,28,39]$, and those with greater awareness or concern about skin damage or skin cancer, or knowing someone with skin cancer $[4,18,28]$. Lawler et al. found varying degrees of sex differences depending on what was assessed: women were more likely to wear sleeveless tops and short shorts, more likely to wear sunscreen (though not in all sports), but not more likely to reapply it (no difference between sexes) [21]. Single marital status has been associated with higher risk of sunburn $[15,25]$. Duarte found that education level affected knowledge of skin cancer but did not affect behaviour [15]. Price et al. and Buller et al. found that those with burn-predisposed skin types were more likely to protect their skin $[6,28]$.

\section{Knowledge, Attitudes and Reported Reasons for Safe vs Unsafe Behaviour}

Behaviour is influenced by demographic, environmental, and psychosocial factors [39], such as skin cancer risk perceptions, perceived barriers to sunscreen use, lower perceived benefits and personal norms [19]. Although we cannot assume that knowledge of sun safety always translates to behaviour, the intention to use sunscreen has been associated with more frequent sunscreen use [40,41]. But there remain some contradictory behaviours and opinions: in kitesurfers [14], nearly $80 \%$ agreed that they worried they "might get skin cancer from the sun" and $70.8 \%$ worried about sunburn, yet more than $40 \%$ enjoyed sunbathing. Among 
elite Paralympic sailors, despite $82.1 \%$ reporting concern about skin cancer, $42.9 \%$ enjoyed sunbathing [26]. Other factors to be taken into account are that individuals may underestimate the seriousness of skin cancer [42] and their likelihood of burning [18], or may not seek attention if they feel healthy and do not have obvious skin lesions [31].

Explicit reasons cited for not using sunscreen included forgetfulness and discomfort $[18,29,40]$, greasy feel, burning of eyes, causing acne, being time consuming, inconvenient or messy $[18,40]$, and hindering performance (e.g. slippery hands) [19]. Clothing can also be restrictive or uncomfortable [43].

Getting a suntan may be seen as reflective of a healthy outdoor active lifestyle [44], which has been reflected in so-called health magazines that use "dark-skinned Caucasian" models [45], and include few articles on skin cancer risk reduction [46]. But such opinions are not constant: in a large USA sample of recreational cyclists [40], participants reported they were not interested in tanning; intentions to use sunscreen and actual use correlated with perceived costs and effectiveness and susceptibility to photoaging.

\section{Prevalence of Skin Damage and Skin Cancer in Sporting Populations}

\section{Skin Cancer}

As part of the American College of Sports Medicine (ACSM) 2018 International Roundtable [2], expert participants looked at a pooled analysis [47] that evaluated 12 cohorts with a total of 12,438 melanoma cases. Overall, a high level of physical activity was associated with a greater risk of melanoma relative to low physical activity (hazard ratio, 1.27; 95\% confidence interval [CI], 1.16-1.40) [47]. Eight of the cohorts had hazard ratios of 1.2 or greater (range 1.23-1.90), suggesting "a strong and highly consistent association" [2].

Rosso et al. [48] analysed sun exposure patterns in the aetiology of basal cell carcinoma (BCC) and SCC in a Southern European population. One of their key findings was an increased risk of SCC with increasing exposure beyond a threshold of 70,000 cumulative hours in a lifetime. Beach holidays and water sports were independent risk factors for BCC, although outdoor sports in general were not, and they even noted that outdoor sports seemed to protect against SCC occurrence. For BCC, there was a significant association for water sports with intense exposure (e.g. swimming, surfing, or sailing), but a dose-response relationship was not established. A few years later (1999), a case-control study of risk of BCC and SCC in Switzerland [49] found that sun exposure during recreational activities (outdoor sports) showed a twofold increase in BCC risk, with borderline statistical significance as an independent effect $(P=0.05)$; sunburn was the highest independent risk factor for BCC (odds ratio [OR] 2.4 for more than three sunburns in a lifetime with a significant linear trend), while SCC risk was related to lifetime cumulative exposure [49].

A study of skin cancer risk factors in a German population found that history of winter sports in childhood had an OR of 1.7 for BCC, indicating possible increased risk. Mountaineering in childhood was actually associated with reduced melanoma risk, compared with BCC or healthy controls [50].

Participation in outdoor sports was identified as a risk factor for melanoma in an Argentinian study $(\mathrm{OR}=3.2$ for more than 5790 lifetime accumulated hours) [51], while Zanetti found that sun exposure during leisure activities in general showed only slightly above-unit OR for melanoma, which was not significant [36]. A Danish study including 28,000 people followed up over 14 years reported, in the men only, a highly significant $(P=0.001)$ direct association with NMSC for vigorous activity vs low activity, with a rate ratio of 1.72 (95\% CI 1.23-2.40) [52].

Dozier et al. found a significantly higher incidence of BCC in surfers than a control population: $16.3 \%$ vs $3.2 \%$ [53]. In the surfers (mean age 29.7 years; 90\% male), 20/49 (41\%) had actinic keratoses (AK), 8 (16\%) had BCC, and none had SCC or melanoma; 18 had clinically atypical moles. These rates were higher than the control for BCC (statistically significant), and higher but not statistically significant 
for $\mathrm{AK}$ and atypical moles. Climstein et al. reported on the lifetime prevalence of skin cancer (melanoma, SCC and BCC) in 1348 Australian recreational and competitive surfers [54]: BCC was the most common (6.8\%), followed by melanoma (1.4\%) then SCC $(0.6 \%)$. The relative risk of skin cancer was significantly higher in competitive than recreational surfers [54], and years surfing was the most significant risk factor. Noble-Jerks' survey [23] of retired cricketers did not find a higher rate of skin cancer (any type) than in the general population: $38 \%$ of their respondents had been diagnosed with at least one skin cancer [23].

Zink's study of mountain and ski guides found that $43.5 \%$ had a diagnosis of NMSC or a premalignant lesion (mostly AK) [30]. This may be more suitably attributed to the category of occupational exposure, with certain factors beyond the control of the individual. In some countries (e.g. Germany), KC (formerly NMSC) is now recognised as an occupational disease [30].

\section{Surrogate Data}

Skin cancer data are not always available. Often, other variables that represent increased risk of $\mathrm{KC}$ and/or melanoma are used, such as exposure dose or number of naevi [36], total exposure dose being more closely associated with SCC, while melanoma are more associated with intense sun exposure during infancy.

\section{Noncancerous and Precancerous Lesions}

Mahé et al. [55] looked at risk of UV-related skin lesions in children. In those who played outdoor sports, the naevus count and acquired naevus count were higher, reaching statistical significance. Richtig et al. studied potential melanoma markers in 150 marathon runners (all white, mean age 39.6 years, mostly phototype II and III) [38]. They assessed lentigines and naevi on the shoulder and buttock, finding statistically significant differences between the two areas for naevi and lentigines; $17.3 \%$ had more than 50 naevi and $35.3 \%$ had atypical naevi. Number of lentigines correlated with lifetime sunburn history and type of sportswear, and number of naevi correlated with training parameters (heart rate, training velocity, physical strain). Ambros-Rudolph et al. [11] also found that marathon runners had significantly more atypical melanocytic naevi and solar lentigines than their control population [11]. Del Boz et al. found a high prevalence of skin cancer and $\mathrm{AK}$ in golf players: about $10.7 \%$ and $40 \%$, respectively [56]; by comparison, indoor workers at the same resort had no diagnoses of skin cancer and only 1.7\% had AK [56].

Solar radiation is also a key driver of skin aging [57], accelerating the formation of uneven pigmentation, wrinkles, and sagging skin; while not pathological, this could serve as a further motivation for protection.

\section{Exposure Doses}

Exposure dose is affected by geographic location, body position [58] and other individual sport characteristics; multiple studies have measured and/or calculated UV exposure, as summarised in Table 1.

The International Commission on NonIonizing Radiation Protection (ICNIRP) and American Conference of Governmental Industrial Hygienists (ACGIH) set an exposure limit for ultraviolet radiation of $0.3 \mathrm{MED}$ per $8 \mathrm{~h}$ [59-61]. At a cycling event in the Australian winter, the mean daily UV exposure, with some variation across body sites, exceeded this limit [59], and the authors suggested these doses would be generalizable to Canadian, Scandinavian and British populations in summer. Tour de Suisse cyclists were exposed to more than 30 times this international exposure limit each day [60].

On the basis of exposure times, Downs et al. [62] calculated the relative risk of developing BCC or SCC for people with a golfing habit compared with other regular office workers, assuming a lifelong regular habit. This was 1.11 (forearm) and 1.16 (upper back) for BCC and 1.15 (forearm) and 1.22 (upper back) for SCC [62].

Exposure doses are further influenced by setting. Rigel et al. noted, in an alpine ski environment, a $2-3 \%$ increase in UV irradiance for each $100 \mathrm{~m}$ of altitude, and up to a $40 \%$ increase due to the albedo (reflectance) of snow [8]. They concluded [63] that skiers with type I 
and II skin are repeatedly exposed to erythemal and suberythemal levels of UV radiation that can cause photodamage and potentially increase their risk of skin cancer [63]. Downs et al. [64] calculated the exposure for athletes expected to compete at the 2020 Olympics (Tokyo) across 20 outdoor sporting disciplines, taking into account body position, event duration, event schedule, atmospheric parameters, UV surface albedo, and protection by clothing, to determine the likely biologically effective UV dose received [64] (Table 1).

\section{Previous Photoprotection Campaigns}

In addition to forming a component of many general sun safety campaigns, some interventions have specifically targeted sporting environments.

Free beachfront skin screening was offered to an at-risk population of surfers, at a competitive surf event in Texas [53]. The opportunity was promoted by the surf association that organised the event, through correspondence with its members. If suspicious lesions were identified, participants were advised to seek medical attention, and this was followed up in writing. Compared with the control group, they found higher rates of BCC among the surfer population, suggesting that targeting this population was a more productive approach [53].

The effects of training youth soccer coaches about skin cancer risk was assessed in a pilot study in Georgia, USA [43]. Training involved a seminar and a booklet of prevention strategies and information. The coaches who had undergone this training then showed better understanding of the need to apply sunscreen 20-30 min before sun exposure, but not about protective clothing, or the recommended frequency of skin examination [43]. Later, some of the same authors assessed the effect of healthcare providers' counselling to soccer participants' parents and coaches [71], finding that those who received counselling had better skin cancer knowledge, recognition of skin changes, and protective behaviours [71].

"Go Sun Smart" was a multimedia educational campaign used in ski resorts in North
America. It was initially tested in children attending ski schools [72] then studied in a wider adult population [73]. In the initial randomized controlled trial (control group of ski schools with no intervention), it did not produce sun safety improvements overall, but the authors noted a possible ceiling effect from already high sunscreen use, and a low rate of staff conversations with parents about sun protection [72]. In adult skiers [73], the programme did not increase protection behaviours compared with control resorts, although within the intervention resorts, those that had greater recall of seeing the campaign messages had better sun protection behaviour [73]. Later replications [74] including an enhanced dissemination strategy [75] did not have favourable results.

A campaign aimed at golf players was conducted at six golf courses in Marbella, Spain, in 2011 [56], which included a questionnaire, a skin examination, and advice on sun protection measures, self-examination, and sunscreen use. More than $90 \%$ of the participants rated the campaign positively and reported they intended to improve their habits including skin examination [56].

In 2017, Ally et al. [76] assessed the impact of an educational intervention ("SUNSPORT": Stanford University Network for Sun Protection, Outreach, Research and Teamwork) in 846 student athletes: 116 before the intervention and 730 after the intervention (unpaired data). The intervention consisted of dermatologist-led education given to athletes during an annual skin examination, as well as presentations and handouts to teams, including coaches and trainers, on skin cancer and protection. Following the intervention, the primary outcome of sunscreen use at least 4 days per week increased from $26 \%$ to $36 \%$, which was statistically significant. They also found that more students received sun safety recommendations from their coaches (26-57\%), and more recognised that athletes were at increased risk of skin cancer (54-67\%) (both statistically significant) [76].

In 2020, Horsham et al. gave out UV detection stickers to adolescent rugby players, at a 2-day event (Australia). The stickers indicated 
when sunscreen was no longer effective, and sunscreen was provided free to access. This approach resulted in a more than threefold improvement in sunscreen use (day 2 with stickers vs day 1 without stickers) [77].

Stölzel et al. developed the Clever in Sun and Shade Program (CSSP) for sports schools in Germany, using the participation of the target audience in an aim to increase the likelihood of success [78]. They found that by adapting the content on the basis of student athletes' feedback, they got more positive opinions on the programme materials. They noted that students actually suggested using a "fear" technique in the materials, and that interventions should be targeted with specific instructions e.g. "don't forget your shirt" rather than vague messages. This point was echoed by coaches who also indicated they wanted a clear message on what actions to take [78].

\section{Discussion and Sport-Specific Recommendations}

The previous studies provide evidence that participating in outdoor sports increases the risk of photodamage, melanocytic naevi and skin cancer. The effect of photoprotection campaigns is limited because the use of some clothes, hats and even sunscreens is rejected by sports players as a result of their use being unsuitable, uncomfortable or even hazardous under specific circumstances (e.g. stinging eyes or slippery fingers). Recommendations are needed to customize photoprotection to different sports to make it feasible and effective. Based on the literature, the following recommendations are proposed:

Individual Sun Protection Measures for Sports

- Photoprotection should be practised by all sports participants across all skin phototypes.

- We suggest applying sunscreen irrespective of the UV index (UVI). While general advice has been to apply sunscreen on days when the UVI is over 3, prolonged exposure at lower levels can still result in high UV exposure and even sunburn [79].
- Where reasonable, training schedules should be adjusted to avoid midday exposure (10 am-2 pm).

- Clothes provide good, broad-spectrum UV and visible light protection [80]. Athletes should take advantage of sport-specific clothes, such as rash vests for surfing [54].

- Protective hats or caps, adapted to the sport, are essential, in addition to efficient UVfiltering sunglasses, when possible.

- Sunscreen should be at least SPF 30. SPF is a measure of UVB protection (SPF 30 meaning it would take 30 times longer for erythema to develop vs unprotected skin, in a laboratory setting), but sunscreen should be broadspectrum to include balanced UVA protection.

- Higher SPFs, e.g. SPF 50 and up to 100, are likely to be beneficial for snow sports and water sports such as surfing or sailing, especially in spring and summer when the UVI is high or very high [81].

- Sunscreen should be applied in sufficient amounts (approximately $2 \mathrm{mg} / \mathrm{cm}^{2}$ ), at least $30 \mathrm{~min}$ before exposure, then reapplied every $2-3 \mathrm{~h}$ of exposure; reapplication is particularly important in water sports.

- Secondary performance attributes matter: sunscreens that are easy to spread, nongreasy, non-sticky, suitable for use on wet skin, non-irritating to the eyes, sweat resistant, and not causing loss of grip are more likely to be used consistently. New methods for assessing these qualities will be needed.

- Routine self-examination of the skin and consultation at least once a year [13].

- Avoid photosensitising agents [82].

- Oral supplementation with antioxidants should be considered [83]. This does not provide an immediate effect, and should be considered an add-on to the above recommendations, not a substitute.

- Use of personalised indicators such as UV detection stickers [77], or electronic/phone apps to track personal UV exposure [84] could increase adequate sunscreen use. 


\section{Organisational Measures and Photoprotection Campaigns}

- Uniform/clothing policies to ensure skin coverage and eye photoprotection at clubs and competitions.

- Visual and verbal prompting to remind athletes to use and reapply sunscreen during training or competition $[19,28]$.

- Sunscreens should be easily available in accessible locations such as changing rooms, pitch-side etc. $[15,19]$.

- It is important that those involved in the sport (coaches, trainers etc.) encourage athletes to protect themselves against the sun, e.g. not encouraging them to take their top off to play [1].

- Use of elite athletes as role models [64].

- Organisers could send advance reminders to those attending sporting events to bring sunscreen and protective clothing (e.g. by text message, email).

- Sunscreen advertising can be used to inform users, participants or spectators how to apply sunscreen adequately $[46,85]$.

\section{LIMITATIONS OF THIS ARTICLE}

Much of the data on photoprotection habits is self-reported and therefore subject to reporting bias. Convenience sampling at sporting events is frequently used.

We limited our search to the sports setting. This means that we excluded some studies (e.g. in schools, summer camps, at the beach) with subgroups involving outdoor activities. The setting of outdoor workers has some overlap with sports, and we drew a somewhat artificial boundary for inclusion: for example, some studies that combined skiers (leisure) and ski instructors (professional) were included, while others of outdoor workers were excluded. Likewise, discriminating between those participating in sports, working in sports settings, and simply being outdoors at a sports event is difficult: for example, tennis players, tennis umpires, tennis coaches, and spectators at the same event may have different needs and motivations.
Our recommendations are based on peer-reviewed literature, clinical experience, and group discussion, but did not follow a standardised methodology for consensus recommendations, which represents a limitation. We write from a dermatological perspective, focusing on the skin, but appropriate eye protection measures should be used.

\section{CONCLUSIONS}

Many athletes are used to receiving health promotion messages and taking steps to reduce risk of injury: ensuring good nutrition and hydration, warming up and cooling down, using protective safety equipment... these are well ingrained into many athletes' routines already. Perhaps because the more harmful effects of solar radiation are seen over the long term and may not immediately impair performance, they are not prioritised, but every effort should be made to make sun protection easy and normalise protective behaviours in this population.

\section{ACKNOWLEDGEMENTS}

The authors thank the photoprotection board of ISDIN, including Jean Krutmann, Thierry Passeron, Henry W Lim, Yolanda Gilaberte, Giovanni Leone, Sergio Schalka, Philippe Masson, Corinne Granger and Carles Trullàs, who initiated and endorsed this article.

Funding. ISDIN funded publication costs including rapid service fee.

Authorship. All named authors meet the International Committee of Medical Journal Editors (ICMJE) criteria for authorship for this article, take responsibility for the integrity of the work as a whole, and have given their approval for this version to be published.

Author Contributions. The idea for the article was conceived by Corinne Granger, Carles Trullàs, and Yolanda Gilaberte. The literature search and draft article were done by a 
medical writer (Jane Marshall, freelance) and Yolanda Gilaberte. All authors (Corinne Granger, Carles Trullàs, Yolanda Gilaberte, and Magdalena de Troya-Martín) critically revised the manuscript for intellectual content, interpretation of data, and substantial editing. All authors approved the final version.

Medical Writing, Editorial, and Other Assistance. A medical writer (J. Marshall, freelance) assisted in drafting the manuscript, with costs funded by ISDIN.

Disclosures. Corinne Granger and Carles Trullàs are employees of ISDIN. Yolanda Gilaberte served as a consultant for ISDIN, Roche Posay, and Cantabria Labs, received research grants from Vichy and Galderma, and provided lectures for ISDIN, Roche Posay, Vichy, Rilastil, IFC and Pierre Fabre. Magdalena de Troya-Martín has nothing to disclose.

Compliance with Ethics Guidelines. This article is based on previously conducted studies and does not contain any new studies with human participants or animals performed by any of the authors.

Data Availability. Data sharing not applicable to this article as no datasets were generated or analysed during the current study.

Open Access. This article is licensed under a Creative Commons Attribution-NonCommercial 4.0 International License, which permits any non-commercial use, sharing, adaptation, distribution and reproduction in any medium or format, as long as you give appropriate credit to the original author(s) and the source, provide a link to the Creative Commons licence, and indicate if changes were made. The images or other third party material in this article are included in the article's Creative Commons licence, unless indicated otherwise in a credit line to the material. If material is not included in the article's Creative Commons licence and your intended use is not permitted by statutory regulation or exceeds the permitted use, you will need to obtain permission directly from the copyright holder. To view a copy of this licence, visit http://creativecommons.org/licenses/by$\mathrm{nc} / 4.0 /$.

\section{REFERENCES}

1. Adams BB. Dermatologic disorders of the athlete. Sports Med. 2002;32(5):309-21.

2. Patel AV, Friedenreich CM, Moore SC, et al. American College of Sports Medicine roundtable report on physical activity, sedentary behavior, and cancer prevention and control. Med Sci Sports Exerc. 2019;51(11):2391-402.

3. Haluza D, Simic S, Moshammer H. Sun exposure prevalence and associated skin health habits: results from the Austrian population-based UV skin risk survey. Int J Environ Res Public Health. 2016;13(1): 141.

4. Christoph S, Cazzaniga S, Hunger RE, Naldi L, Borradori L, Oberholzer PA. Ultraviolet radiation protection and skin cancer awareness in recreational athletes: a survey among participants in a running event. Swiss Med Wkly. 2016;146:w14297.

5. De Luca JF, Adams BB, Yosipovitch G. Skin manifestations of athletes competing in the summer Olympics: what a sports medicine physician should know. Sports Med. 2012;42(5):399-413.

6. Price J, Ness A, Leary S, Kennedy C. Sun-safety behaviors of skiers and snowboarders on the South Island of New Zealand. J Cosmet Dermatol. 2006;5(1):39-47.

7. Allen M, McKenzie R. Enhanced UV exposure on a ski-field compared with exposures at sea level. Photochem Photobiol Sci. 2005;4(5):429-37.

8. Rigel DS, Rigel EG, Rigel AC. Effects of altitude and latitude on ambient UVB radiation. J Am Acad Dermatol. 1999;40(1):114-6.

9. Moehrle M, Koehle W, Dietz K, Lischka G. Reduction of minimal erythema dose by sweating. Photodermatol Photoimmunol Photomed. 2000;16(6): 260-2.

10. Moehrle M. Outdoor sports and skin cancer. Clin Dermatol. 2008;26(1):12-5.

11. Ambros-Rudolph CM, Hofmann-Wellenhof R, Richtig E, Müller-Fürstner M, Soyer HP, Kerl H. Malignant melanoma in marathon runners. Arch Dermatol. 2006;142(11):1471-4. 
12. Vierck HB, Darvin ME, Lademann J, et al. The influence of endurance exercise on the antioxidative status of human skin. Eur J Appl Physiol. 2012;112(9):3361-7.

13. De Castro-Maqueda G, Gutierrez-Manzanedo JV, Ponce-Gonzalez JG, Fernandez-Santos JR, LinaresBarrios M, De Troya-Martin M. Sun protection habits and sunburn in elite aquatics athletes: surfers, windsurfers and Olympic sailors. J Cancer Educ. 2020;35(2):312-20.

14. de Castro MG, Gutierrez-Manzanedo JV, GonzalezMontesinos JL, Vaz Pardal C, Rivas Ruiz F, de Troya MM. Sun exposure and photoprotection: habits, knowledge and attitudes among elite kitesurfers. J Cancer Educ. 2020;27:1-7.

15. Duarte AF, Nagore E, Silva JNM, Picoto A, Pereira AC, Correia OJC. Sun protection behaviour and skin cancer literacy among outdoor runners. Eur J Dermatol. 2018;28(6):803-8.

16. Purim KS, Leite N. Sports-related dermatoses among road runners in Southern Brazil. An Bras Dermatol. 2014;89(4):587-92.

17. Fernandez-Morano T, de Troya-Martin M, RivasRuiz F, et al. Sun exposure habits and sun protection practices of skaters. J Cancer Educ. 2017;32(4): 734-9.

18. Wysong A, Gladstone H, Kim D, Lingala B, Copeland J, Tang JY. Sunscreen use in NCAA collegiate athletes: identifying targets for intervention and barriers to use. Prev Med. 2012;55(5):493-6.

19. Berndt NC, O'Riordan DL, Winkler E, McDermott L, Spathonis K, Owen N. Social cognitive correlates of young adult sport competitors' sunscreen use. Health Educ Behav. 2011;38(1):6-14.

20. Lawler S, McDermott L, O'Riordan D, et al. Relationships of sun-protection habit strength with sunscreen use during outdoor sport and physical activity. Int J Environ Res Public Health. 2012;9(3): 916-23.

21. Lawler S, Spathonis K, Eakin E, Gallois C, Leslie E, Owen N. Sun exposure and sun protection behaviours among young adult sport competitors. Aust N Z J Public Health. 2007;31(3):230-4.

22. Walker N, Love TD, Baker DF, et al. Knowledge and attitudes to vitamin $\mathrm{D}$ and sun exposure in elite New Zealand athletes: a cross-sectional study. J Int Soc Sports Nutr. 2014;11(1):47.

23. Noble-Jerks J, Weatherby RP, Meir R. Self-reported skin cancer protection strategies and location of skin cancer in retired cricketers: a case study from membership of the Emu Cricket Club. J Sci Med Sport. 2006;9(6):441-5.

24. Rivas-Ruiz F, Fernandez-Morano T, Gilaberte Y, Garcia-Montero P, Blazquez-Sanchez N, de TroyaMartin M. Sun exposure and long-distance runners on the Spanish Costa del Sol: habits, attitudes, and knowledge. Actas Dermosifiliogr. 2021;112(6): 541-5.

25. Garcia-Malinis AJ, Gracia-Cazana T, Zazo M, et al. Sun protection behaviors and knowledge in mountain marathon runners and risk factors for sunburn. Actas Dermosifiliogr (Engl Ed). 2021;112(2):159-66.

26. Gutiérrez-Manzanedo JV, De Castro-Maqueda G, Caraballo Vidal I, et al. Sun-related behaviors, attitudes and knowledge among Paralympic sailors. Disabil Health J. 2021;14(3):101095.

27. Doncel Molinero D, Ruiz Paulano M, Rivas Ruiz F, et al. Sun protection behaviour and sunburns in Spanish cyclists. J Cancer Educ. 2020;27:1-8.

28. Buller DB, Andersen PA, Walkosz BJ, et al. Compliance with sunscreen advice in a survey of adults engaged in outdoor winter recreation at high-elevation ski areas. J Am Acad Dermatol. 2012;66(1): $63-70$.

29. De Castro-Maqueda G, Gutierrez-Manzanedo JV, Lagares-Franco C, Linares-Barrios $M$, de TroyaMartin M. Photoprotection practices, knowledge and sun-related skin damage in Spanish beach handball players. PeerJ. 2019;7:e7030.

30. Zink A, Koch E, Seifert F, Rotter M, Spinner CD, Biedermann T. Nonmelanoma skin cancer in mountain guides: high prevalence and lack of awareness warrant development of evidence-based prevention tools. Swiss Med Wkly. 2016. https:// doi.org/10.4414/smw.2016.14380.

31. Zink A, Thome F, Schielein M, Spinner CD, Biedermann T, Tizek L. Primary and secondary prevention of skin cancer in mountain guides: attitude and motivation for or against participation. J Eur Acad Dermatol Venereol. 2018;32(12):2153-61.

32. de Galvez MV, Ruiz Sanchez JM, Navarrete-de Galvez $M$, et al. Sun exposure risks in athletes who were recipients of solid organ and bone marrow transplants. J Am Acad Dermatol. 2019;81(1):253-5.

33. Holman DM, Berkowitz Z, Guy GP Jr, Hartman AM, Perna FM. The association between demographic and behavioral characteristics and sunburn among US adults-National Health Interview Survey, 2010. Prev Med. 2014;63:6-12. 
34. Petersen B, Thieden E, Lerche CM, Wulf HC. Validation of self-reported erythema: comparison of self-reports, researcher assessment and objective measurements in sun worshippers and skiers. J Eur Acad Dermatol Venereol. 2013;27(2):214-9.

35. Kikuchi-Numagami K, Suetake T, Yanai M, Takahashi $M$, Tanaka $M$, Tagami $H$. Functional and morphological studies of photodamaged skin on the hands of middle-aged Japanese golfers. Eur J Dermatol. 2000;10(4):277-81.

36. Zanetti R, Rosso S, Martinez C, et al. Comparison of risk patterns in carcinoma and melanoma of the skin in men: a multi-centre case-case-control study. Br J Cancer. 2006;94(5):743-51.

37. de Castro MG, Gutiérrez-Manzanedo JV, GonzálezMontesinos JL, Vaz Pardal C, Rivas Ruiz F, de Troya MM. Sun exposure and photoprotection: habits, knowledge and attitudes among elite kitesurfers. J Cancer Educ. 2020. https://doi.org/10.1007/ s13187-020-01838-7.

38. Richtig E, Ambros-Rudolph CM, Trapp M, et al. Melanoma markers in marathon runners: increase with sun exposure and physical strain. Dermatology. 2008;217(1):38-44.

39. Janssen E, van Kann D, de Vries H, Lechner L, van Osch L. Sun protection during snow sports: an analysis of behavior and psychosocial determinants. Health Educ Res. 2015;30(3):380-7.

40. Petty KN, Knee CR, Joseph AK. Sunscreen use among recreational cyclists: how intentions predict reported behavior. J Health Psychol. 2013;18(3): 439-47.

41. Janssen E, van Osch $\mathrm{L}$, de Vries $\mathrm{H}$, Lechner L. Examining direct and indirect pathways to health behaviour: the influence of cognitive and affective probability beliefs. Psychol Health. 2013;28(5): 546-60.

42. Boggild AK, From L. Barriers to sun safety in a Canadian outpatient population. J Cutan Med Surg. 2003;7(4):292-9.

43. Parrott R, Duggan A, Cremo J, Eckles A, Jones K, Steiner C. Communicating about youth's sun exposure risk to soccer coaches and parents: a pilot study in Georgia. Health Educ Behav. 1999;26(3): 385-95.

44. Lupton D, Gaffney D. Discourses and practices related to suntanning and solar protection among young Australians. Health Educ Res. 1996;11(2): 147-59.

45. Basch CH, Hillyer GC, Ethan D, Berdnik A, Basch CE. Tanning shade gradations of models in mainstream fitness and muscle enthusiast magazines: implications for skin cancer prevention in men. Am J Mens Health. 2015;9(4):301-6.

46. Basch CH, Ethan D, Hillyer GC, Berdnik A. Skin cancer prevention coverage in popular US women's health and fitness magazines: an analysis of advertisements and articles. Glob J Health Sci. 2014;6(4): $42-8$.

47. Moore SC, Lee IM, Weiderpass E, et al. Association of leisure-time physical activity with risk of 26 types of cancer in 1.44 million adults. JAMA Intern Med. 2016;176(6):816-25.

48. Rosso S, Zanetti R, Martinez C, et al. The multicentre south European study "Helios". II: Different sun exposure patterns in the aetiology of basal cell and squamous cell carcinomas of the skin. $\mathrm{Br} \mathrm{J}$ Cancer. 1996;73(11):1447-54.

49. Rosso S, Joris F, Zanetti R. Risk of basal and squamous cell carcinomas of the skin in Sion, Switzerland: a case-control study. Tumori. 1999;85(6): 435-42.

50. Kaskel P, Lange U, Sander S, et al. Ultraviolet exposure and risk of melanoma and basal cell carcinoma in Ulm and Dresden, Germany. J Eur Acad Dermatol Venereol. 2015;29(1):134-42.

51. Loria D, Matos E. Risk factors for cutaneous melanoma: a case-control study in Argentina. Int J Dermatol. 2001;40(2):108-14.

52. Schnohr $\mathrm{P}$, Gronbaek $\mathrm{M}$, Petersen L, Hein HO, Sorensen TI. Physical activity in leisure-time and risk of cancer: 14-year follow-up of 28,000 Danish men and women. Scand J Public Health. 2005;33(4):244-9.

53. Dozier S, Wagner RF Jr, Black SA, Terracina J. Beachfront screening for skin cancer in Texas Gulf coast surfers. South Med J. 1997;90(1):55-8.

54. Climstein M, Furness J, Hing W, Walsh J. Lifetime prevalence of non-melanoma and melanoma skin cancer in Australian recreational and competitive surfers. Photodermatol Photoimmunol Photomed. 2016;32(4):207-13.

55. Mahé E, Beauchet A, de Paula CM, et al. Outdoor sports and risk of ultraviolet radiation-related skin lesions in children: evaluation of risks and prevention. Br J Dermatol. 2011;165(2):360-7.

56. del Boz J, Fernandez-Morano T, Padilla-Espana L, Aguilar-Bernier M, Rivas-Ruiz F, de Troya-Martin M. Skin cancer prevention and detection campaign at golf courses on Spain's Costa del Sol. Actas Dermosifiliogr. 2015;106(1):51-60. 
57. Clatici VGRD, Dalle C, Voicu C, et al. Erceived age and life style. The specific contributions of seven factors involved in health and beauty. Maedica (Bucur). 2017;12(3):191-201.

58. Downs NJ, Parisi AV, Schouten PW, Igoe DP, De Castro-Maqueda G. The simulated ocular and whole-body distribution of natural sunlight to kiteboarders: a high-risk case of UVR exposure for athletes utilizing water surfaces in sport. Photochem Photobiol. 2020;96(4):926-35.

59. Kimlin MG, Martinez N, Green AC, Whiteman DC. Anatomical distribution of solar ultraviolet exposures among cyclists. J Photochem Photobiol B. 2006;85(1):23-7.

60. Moehrle M, Heinrich L, Schmid A, Garbe C. Extreme UV exposure of professional cyclists. Dermatology. 2000;201(1):44-5.

61. ICNIRP, IRPA. Protection ICONIR. ICNIRP guidelines on UV radiation exposure limits. Health Phys. 1996;71:978.

62. Downs NJ, Schouten PW, Parisi AV, Turner J. Measurements of the upper body ultraviolet exposure to golfers: non-melanoma skin cancer risk, and the potential benefits of exposure to sunlight. Photodermatol Photoimmunol Photomed. 2009;25(6): 317-24.

63. Rigel EG, Lebwohl MG, Rigel AC, Rigel DS. Ultraviolet radiation in alpine skiing: magnitude of exposure and importance of regular protection. Arch Dermatol. 2003;139(1):60-2.

64. Downs NJ, Axelsen T, Schouten P, Igoe DP, Parisi $\mathrm{AV}$, Vanos J. Biologically effective solar ultraviolet exposures and the potential skin cancer risk for individual gold medalists of the 2020 Tokyo Summer Olympic Games. Temperature (Austin). 2020;7(1):89-108.

65. Serrano MA, Cañada J, Moreno JC. Erythemal ultraviolet exposure of cyclists in Valencia, Spain. Photochem Photobiol. 2010;86(3):716-21.

66. Serrano MA, Cañada J, Moreno JC. Ultraviolet exposure for different outdoor sports in Valencia, Spain. Photodermatol Photoimmunol Photomed. 2011;27(6):311-7.

67. Serrano MA, Canada J, Moreno JC, Members of The Valencia Solar Radiation Research Group. Erythemal ultraviolet solar radiation doses received by young skiers. Photochem Photobiol Sci. 2013;12(11):1976-83.

68. Serrano MA, Canada J, Moreno JC, Gurrea G. Personal UV exposure for different outdoor sports. Photochem Photobiol Sci. 2014;13(4):671-9.
69. Moehrle M. Ultraviolet exposure in the Ironman triathlon. Med Sci Sports Exerc. 2001;33(8):1385-6.

70. Gurrea Ysasi G, Moreno JC, Serrano MA. Ultraviolet erythematic radiation dose received by golfers in winter, Valencia. Photochem Photobiol. 2014;90(5):1170-3.

71. Robinson JD, Silk KJ, Parrott RL, Steiner C, Morris SM, Honeycutt C. Healthcare providers' sun-protection promotion and at-risk clients' skin-cancerprevention outcomes. Prev Med. 2004;38(3):251-7.

72. Walkosz B, Voeks J, Andersen P, et al. Randomized trial on sun safety education at ski and snowboard schools in western North America. Pediatr Dermatol. 2007;24(3):222-9.

73. Walkosz BJ, Buller DB, Andersen PA, et al. Increasing sun protection in winter outdoor recreation a theory-based health communication program. Am J Prev Med. 2008;34(6):502-9.

74. Andersen PA, Buller DB, Walkosz BJ, et al. Testing a theory-based health communication program: a replication of Go Sun Smart in outdoor winter recreation. J Health Commun. 2009;14(4):346-65.

75. Walkosz BJ, Buller DB, Andersen PA, et al. Translation of a ski school sun safety program to north American ski and snowboard schools. Health Promot Pract. 2015;16(4):560-70.

76. Ally MS, Swetter SM, Hirotsu KE, et al. Promoting sunscreen use and sun-protective practices in NCAA athletes: impact of SUNSPORT educational intervention for student-athletes, athletic trainers, and coaches. J Am Acad Dermatol. 2018;78(2):289-92 e2.

77. Horsham C, Ford H, Hacker E. Promoting sunscreen use in adolescents playing outdoor sports using UV detection stickers. Prev Med Rep. 2020;19:101166.

78. Stölzel F, Wolff M, Fieber V, et al. UV protection for young athletes: using participatory program planning to develop a sports schools program. Environ Health Prev Med. 2020;25(1):39.

79. Igoe DP, Amar A, Schouten P, Parisi AV, Turner J. Assessment of biologically effective solar ultraviolet exposures for court staff and competitors during a major Australian tennis tournament. Photochem Photobiol. 2019;95(6):1461-7.

80. Ghazi S, Couteau C, Coiffard LJ. How to guarantee adequate sun protection for a young sportsperson. J Dtsch Dermatol Ges. 2011;9(6):470-4.

81. Williams JD, Maitra P, Atillasoy E, Wu MM, Farberg AS, Rigel DS. SPF 100+ sunscreen is more protective against sunburn than SPF 50+ in actual use: results 
of a randomized, double-blind, split-face, natural sunlight exposure clinical trial. J Am Acad Dermatol. 2018;78(5):902-10.e2.

82. Conklin RJ. Common cutaneous disorders in athletes. Sports Med. 1990;9(2):100-19.

83. De Gálvez MV. Antioxidants in photoprotection: do they really work? Actas Dermosifiliogr. 2010;101(3):197-200.
84. Snyder A, Valdebran M, Terrero D, Amber KT, Kelly KM. Solar ultraviolet exposure in individuals who perform outdoor sport activities. Sports Med Open. 2020;6(1):42.

85. Lynch BM, Dunn J. Scoreboard advertising at sporting events as a health promotion medium. Health Educ Res. 2003;18(4):488-92. 